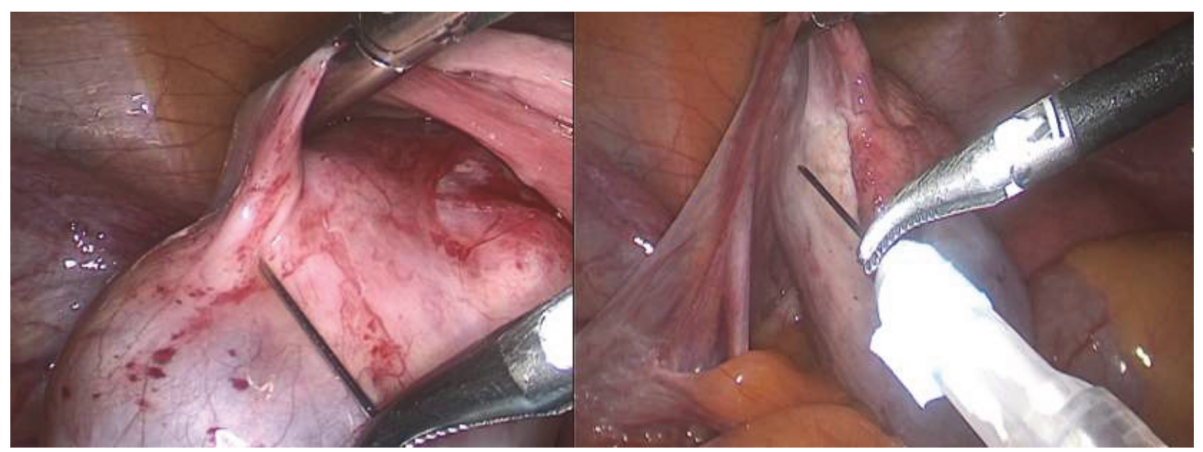

Abstract 834 Figure 1 Albumin [99mTc] Tc-nanocolloid injection into the utero-ovarian and infundibulo-pelvic ligaments
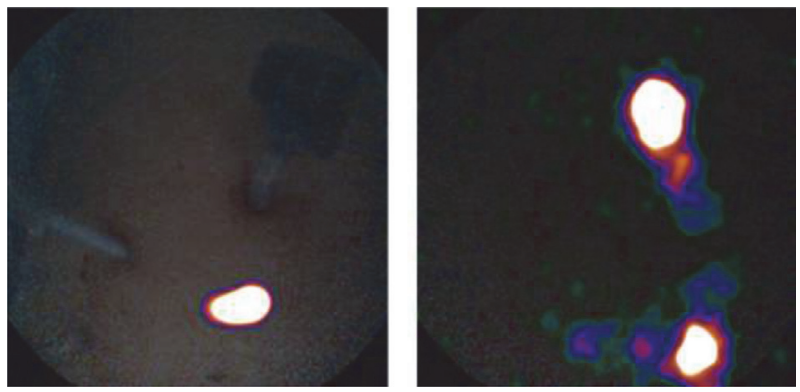

Abstract 834 Figure 2 Images acquired with the portable gamma camera at 15 minutes and at 90 minutes postinjection. Paraortic drainage is observed.

detected in 18/20 cases (90\%) with exclusive paraortic drainage in $5 / 18(28 \%)$, pelvic in $1 / 18(6 \%)$ and in both territories in $12 / 18(66 \%)$. Overall para-aortic drainage was observed in $17 / 18$ (94\%) patients (35\% supramesenteric, 30\% at the level of the inferior mesenteric artery, and $35 \%$ inframesenteric). $100 \%$ of aortic SLNs were detected with a gamma probe after being visualized with the gamma camera. In the 8 patients who underwent lymphadenectomy, 1 case had positive nodes diagnosed by ultrastaging and the rest of the lymph nodes were negative. No complications related to the technique were observed.

Conclusion* The SLN technique is feasible and safe. The intraoperative gamma camera shows the lymphatic map and is especially useful in the paraortic region.

\section{FEASIBILITY OF DIAPHRAGMATIC SURGERY FOR ADVANCED OVARIAN CANCER: A SINGLE INSTITUTION ANALYSIS}

G Candotti ${ }^{*}$, F Sgalambro, A Bergamini, F Cantatore, R Cioffi, P De Marzi, ML Fais, F Galli, E Rabaiotti, G Sabetta, C Saponaro, L Bocciolone. San Raffaele Hospital, Obstetrics and Gynecology, Milano, Italy

\subsection{6/ijgc-2021-ESGO.483}

Introduction/Background* Standard treatment for advanced ovarian cancer patients should be primary cytoreduction following platinum-based chemotherapy. The aim of surgical effort should be the complete removal of all macroscopic disease. Surgery of upper abdomen is often required to obtain optimal cytoreduction. Our objective was to evaluate perioperative features, postoperative complications of patients who underwent diaphragmatic stripping or diaphragmatic resection for advanced ovarian cancer.

Methodology From June 2018 to April 2021, 138 patients underwent cytoreductive surgery for advanced ovarian cancer at San Raffaele Hospital. Forty-one cases were selected, among them 29 underwent diaphragmatic stripping and 12 underwent diaphragmatic full-thickness resection during primary cytoreduction surgery (PCS) or interval debulking surgery (IDS). All surgical procedures were performed by use of bipolar scissors and blunted resection. Data collected included patients' age, all perioperative details and pathological findings, International Federation of Gynecology and Obstetrics stage.

Result(s)* Median age was 60 (range 32-79) years. Median hospital stays were 7 (range 4-26) days. Thirty-five patients $(85 \%)$ obtained optimal cytoreduction with absence of macroscopic disease. Mean loss of blood was $391 \mathrm{ml}( \pm 172)$. Thirtyfour (83\%) patients underwent PDS and 7 (17\%) underwent IDS. Postoperative pleural effusion rate was $14,6 \%$ without any differences between stripping or diaphragmatic resection $(p=0,423)$. One case of pneumothorax was reported in the stripping group.

Conclusion* Diaphragmatic surgery at the time of primary cytoreductive surgery or IDS for advanced ovarian cancer may contribute to the achievement of complete cytoreduction with low perioperative complication rate. Risk of postoperative pleural effusion could be limited by utilization of bipolar scissors and blunted resection to perform surgical procedures.

\section{CANCER-INDUCED ACCELERATED IMMUNOAGING IN WOMEN SUFFERING FROM OVARIAN CANCER}

S Marcoux*, T Kientega, GB Cardin, MF Raynault, AM Mes-Masson, D Provencher, F Rodier. Université de Montréal Faculty of Medicine, Médecine, Montreal, Canada

\subsection{6/ijgc-2021-ESG0.484}

Introduction/Background* Advanced age is a poor prognostic risk factor for most epithelial ovarian cancers. Individuals suffering from socioeconomic deprivation have a lower life expectation and a higher risk for most chronic diseases, including cancer. There is also mounting evidence that undergoing cancer treatments is associated with accelerated cellular aging. Hypothesis: extensive accelerated aging caused by 1) socioeconomic status, 2) cancer itself and 3) cancer therapy is associated with worse prognosis in women suffering from primary ovarian cancer.

Methodology We retrospectively analyzed the immunological age of 488 women diagnosed and treated for a primary 